\title{
Growth, Spectral, Thermal and Dielectric Properties of Triglycine Phosphate Non Linear Optical Crystal
}

\author{
MR Meera ${ }^{\mathrm{a}}$, T Joselin Beaula ${ }^{\mathrm{a}}$, SL Rayar ${ }^{\mathrm{b} *}, \mathrm{~V}$ Bena Jothy ${ }^{\mathrm{a}}$ \\ a Department of Physics and Research Centre, Women's Christian College, Tamil Nadu. \\ ${ }^{b}$ Department of Physics, St Judes Colege, Thoothoor.
}

\begin{abstract}
Received: March 11, 2016; Accepted: March 30, 2016; Published: April 11, 2016
*Corresponding author: SL Rayar, Department of Physics and Research Centre, Women's Christian College, Nagercoil, Tamil Nadu 629001, Phone No: +91 9443692523; E-mail: meeranairmrm17@gmail.com
\end{abstract}

\begin{abstract}
Single crystals of Triglycine Phosphate (TGP) were grown from aqueous solution by slow evaporation technique. Good optical quality single crystals with dimensions $14 \mathrm{X} 10 \mathrm{X} 4 \mathrm{~mm} 3$ were obtained. Single crystal X-ray diffraction analysis reveals that TGP crystals belong to monoclinic system. Various diffracting planes of the grown crystal were identified from the powder X-ray diffraction study. The functional groups present in the structure of the grown crystal are identified by using FTIR spectral analysis. The UV-visible absorption spectra have been recorded to study the optical transmittance in the range from $200 \mathrm{~nm}$ to $800 \mathrm{~nm}$. Thermal stability and melting point of the grown crystal were found by thermal analysis. Dielectric constant and dielectric loss measurements were carried out for different temperatures and frequencies.
\end{abstract}

Keywords: Single Crystal; Slow Evaporation Technique; Singe Crystal X- ray Diffraction; FT-IR; TGA/DTA

\section{Introduction}

Today's technology is seeing a rapid change and its reflection on materials is splendid. The technological development to a larger extent is dependent on the development of crystal growth. Hence the growth of single crystals has become inevitable for any further development in materials science research. In recent years, emphasis has been centred on materials exhibiting large second-order NLO response because of the potential application in telecommunications, optical computing, optical signal processing, laser technology, data storage and image processing $[1,2]$. The development of photonic and optoelectronic technologies rely heavily on the growth of NLO materials with high nonlinear optical responses and the development of novel and more efficient materials [3]. Many NLO crystals grown by mixing amino acids with various organic and inorganic acids have been reported in the literature [4-6]. Amino acids are interesting materials for NLO application as they contain proton donar carboxyl acid (-COO) group and the proton acceptor amino $\left(\mathrm{NH}_{2}\right)$ group in them [7]. Glycine is the smallest among the amino acids, which are found in proteins, and is of special interest as a model for theoretical and experimental studies [8]. The present investigation deals with the growth of Triglycine
Phosphate single crystal by slow solvent evaporation technique and to characterize the grown crystal. The grown crystals were characterized by single crystal and powder X-ray analysis, FTIR and UV spectral analysis, TG/DTA and dielectric measurements. The results of these studies have been discussed.

\section{Experimental}

Triglycine phosphate was obtained by mixing glycine and phosphoric acid in the stoichimetric ratio 3:1 at a constant temperature of $30^{\circ} \mathrm{C}$. The fully reacted solution was filtered and crystalline TGP was obtained by evaporation of filtered solution. Transparent crystals were obtained within a period of 2-3 weeks. Photograph of the grown crystal is as shown in Fig 1

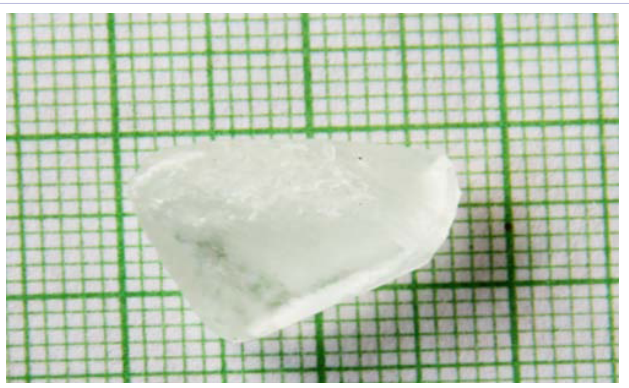

Figure 1: Grown pure TGP crystal.

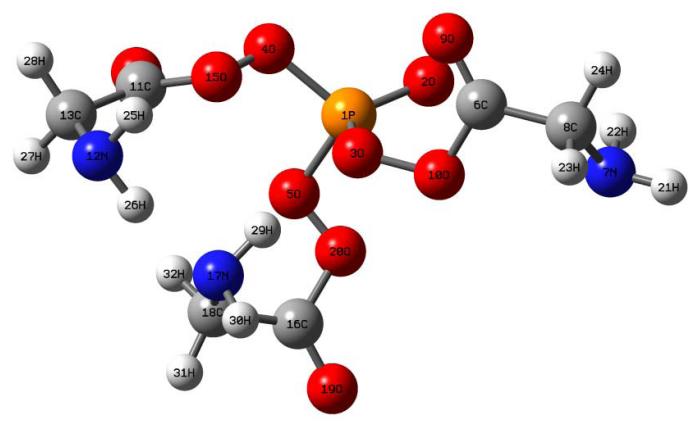

Figure 2: Structure of Triglycine Phosphate crystal. 


\section{Result and Discussion}

\section{Single Crystal XRD Measurement}

Grown TGP crystal is subjected to single crystal XRD to determine the unit cell dimensions and cell volume. A good quality crystal of dimension about $5 \times 4 \times 4 \mathrm{~mm}^{3}$ was selected for the X-ray diffraction studies. Single crystal XRD using a computer controlled Enarf Nonius- CAD4 single crystal diffractometer. Structure of Triglycine Phosphate crystal as shown in Fig 2. Unit cell dimensions determined by single crystal X-ray diffraction analysis are presented in Table 1.

\section{Powder XRD analysis.}

The powdered sample of the grown crystal was also subjected to powder X-ray diffraction analysis using XPert PRO powder X-ray diffractrometer. The peaks observed in the X-ray diffraction spectrum were analysed and the lattice parameters were calculated by the least square fit method. The data obtained by the powder X-ray diffraction analysis is in accordance with the single crystal X-ray diffraction data. It is clear that for the crystal $\mathrm{a} \neq \mathrm{b} \neq \mathrm{c}, \alpha=\gamma=90^{\circ}$ and $\beta \neq 90^{\circ}$, which ensures that the grown TGP crystal is of monoclinic structure [9]. The indexed powder $\mathrm{X}$-ray diffraction pattern is shown in Fig. 3.

\section{FT-IR Spectral Analysis}

FT-IR spectra of TGP crystal shown in figure 4. The FT-IR spectra of pure and doped TGP crystals were recorded in the region 400- $4000 \mathrm{~cm}^{-1}$ using Perkin-Elmer Spectrum-one FT-IR spectrometer. The fundamental modes have been qualitatively assigned,Figure 4.

The functional groups present in the grown crystal were confirmed with the FT-IR spectral analysis. The bands at $3778 \mathrm{~cm}^{-}$ ${ }^{1}$ are assignable to symmetric $\mathrm{NH}_{2}$ deformation mode Asymmetric stretching vibration of $\mathrm{NH}_{2}^{+}$was observed at $3111 \mathrm{~cm}^{-1}$ within the allowed region as the protonation of $\mathrm{NH}_{2}$ group can shift in band position towards the range $3300-3100 \mathrm{~cm}^{-1}$ for asymmetric stretching in amino acid derivatives [10]. The band observed at $2962.97 \mathrm{~cm}^{-1}$ and $2890.02 \mathrm{~cm}^{-1}$ are assignable to $\mathrm{CH}_{2}$ stretching mode. The band at $2230.28 \mathrm{~cm}^{-1}$ is assigned to asymmetric NCO stretching mode. $\mathrm{NH}_{3}$ symmetric and degenerate modes of deformation at $1490.73 \mathrm{~cm}^{-1}$ and $1590.40 \mathrm{~cm}^{-1} . \mathrm{P}=0$ stretching was in $1326.85 \mathrm{~cm}^{-1}$ and $\mathrm{P}-0$ stretching was in $1041.83 \mathrm{~cm}^{-1}$. The results are matching with the reported value [11]. The peak at $926.73 \mathrm{~cm}^{-1}$ are assignable $\mathrm{C}-\mathrm{OH}$ plane mode. The peak at 887.92 $\mathrm{cm}^{-1}$ is due to $\mathrm{C}-\mathrm{C}$ stretching mode. The deformation vibrations of the carboxylate ion are due to the band observed at $682.95 \mathrm{~cm}^{-1}$. The peak at $607.79 \mathrm{~cm}^{-1}$ is due to $\mathrm{C}-\mathrm{N}$ bending mode. Deformation of $\mathrm{COO}^{-}$at $501.99 \mathrm{~cm}^{-1}$.

\section{UV-Vis Spectral Analysis}

Optical transmittance range and transparency cut-off wavelength are the main requirements for device applications. Grown crystals were optically characterised by UV-Vis spectral analysis and is shown in figure 4 . The UV-Vis spectra was recorded in the range of 190-1200 $\mathrm{nm}$ by using Lambda 35 Spectromete. Figure 5.
The absorbance was evident below $204 \mathrm{~nm}$. A complete transparency between 230 and $800 \mathrm{~nm}$ is interesting, as it is very much required for NLO applications of this crystal [12].

\section{Thermal Analysis}

Thermal stability of the grown crystal was identified by Thermo Gravimetric (TG) and differential thermal analysis (DTA). The thermal analysis was carried out simultaneously employing Perkin Elmer thermo gravimetric and differential analyser (Mode: PYRIS DIAMOND) in nitrogen atmosphere heated from 400 to 7300 with a heating rate of $100 \mathrm{C}$ to understand thermal behaviour. The TG/DTA patterns obtained in the present work is shown in Fig.6.

\begin{tabular}{|l|l|l|l|}
\hline \multicolumn{4}{|l|}{ Table 1: Single crystal XRD data of TGP crystal } \\
\hline Chemical Formula & $\left(\mathrm{NH}_{2} \mathrm{CH}_{2} \mathrm{COOH}\right)_{3} \mathrm{H}_{3} \mathrm{PO}_{4}$ & Crystal system & monoclinic \\
\hline Wavelength & $0.71073 \AA$ & Space Group & Pcc2 \\
\hline a & $5.094 \AA$ & $\alpha$ & $90^{\circ}$ \\
\hline b & $11.984 \AA$ & $\beta$ & $111.70^{\circ}$ \\
\hline c & $5.453 \AA$ & $\gamma$ & $90^{\circ}$ \\
\hline cell volume & $309.3(4) \AA^{3}$ & & \\
\hline
\end{tabular}

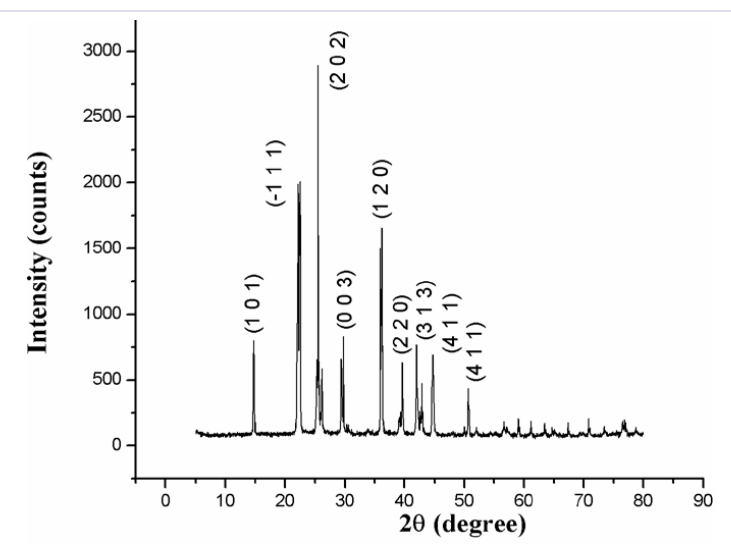

Figure 3: Indexed powder XRD pattern of TGP.

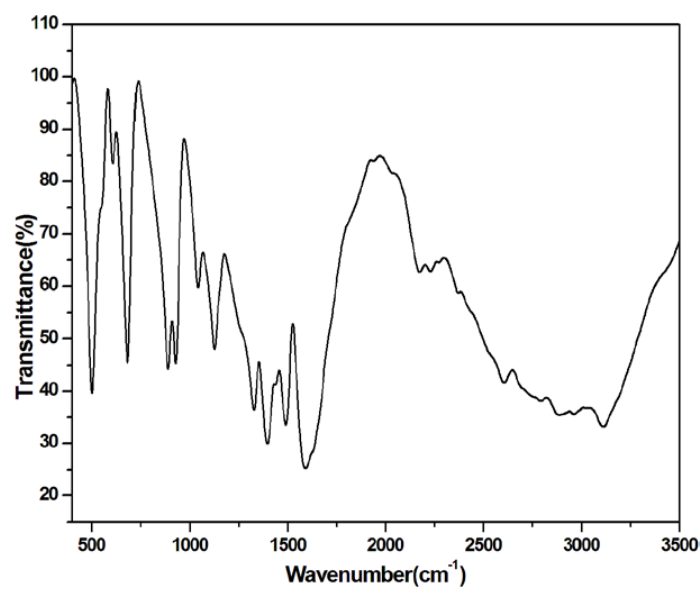

Figure 4: FT-IR spectrum of TGP. 
The TG curve shows no change in weight up to $235^{\circ} \mathrm{C}$, which eliminate the possibility of hydrate or solvate formation of crystals. The major weight loss around $235-285^{\circ} \mathrm{C}$ and minor weight loss in the temperature range $285-385^{\circ} \mathrm{C}$ could be attributed to the sublimation and decomposition of the glycine resulting in the release of $\mathrm{CO}$ and $\mathrm{NH}_{3}$ molecules [13]. The peak at $252.86^{\circ} \mathrm{C}$ in DTA curve indicated the decomposition of the glycine. Thereafter residue remains up to of $800^{\circ} \mathrm{C}$. It is clear that the crystal is thermally stable up to $235^{\circ} \mathrm{C}$.

\section{Dielectric studies}

Dielectric study of the grown crystal was carried out to an accuracy of $\pm 2^{\circ} \mathrm{C}$ using an LCR meter with five different frequencies, viz. $100 \mathrm{~Hz}, 1 \mathrm{KHz}, 10 \mathrm{KHz}, 100 \mathrm{KHz}$ and $1 \mathrm{MHz}$ at various temperatures ranging from $30^{\circ} \mathrm{C}$ to $220^{\circ} \mathrm{C}$. A sample of having silver coating on the opposite faces was placed between the two copper electrodes and a parallel plate capacitor was thus formed.

Variation of dielectric constant $\left(\varepsilon_{\mathrm{r}}\right)$ with frequency and temperature is shown in figure 7. In the present work, $\varepsilon_{\mathrm{r}}$ was found to increase with increase in temperature and decrease with increase in frequency. The increase in dielectric constant with temperature is essentially due to the temperature variation of ionic polarizability. Variation of dielectric loss factor with frequency and temperature is shown in figure 8. Value of $\tan \delta$ shows systematic variation with temperature. Variation of $\sigma_{\text {ac }}$ with frequency and temperature is shown in figure 9. $\sigma_{\text {ac }}$ values found to increase with the increase in temperature, indicating that the grown crystal is normal dielectric material.

\section{Conclusion}

Triglycine phosphate was grown using slow evaporation technique from an aqueous solution

Single crystal of The Singe crystal and Powder XRD analysis confirmed the monoclinic structure of the crystal. Various functional groups have been identified by the FTIR spectral analysis. The wide range of transparency in UV and visible region enables that the grown crystal is to be a good candidate

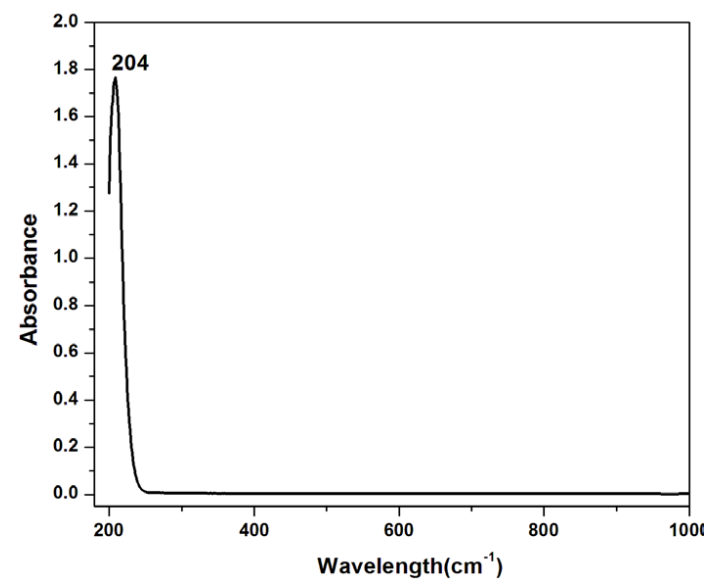

Figure 5: UV-Vis Spectrum of TGP.

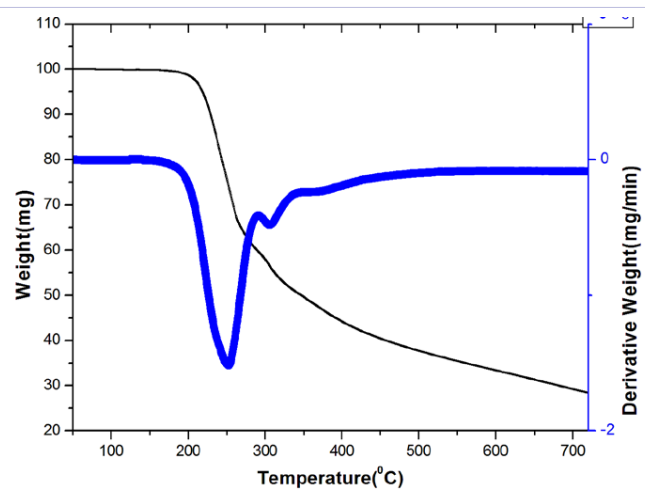

Figure 6:

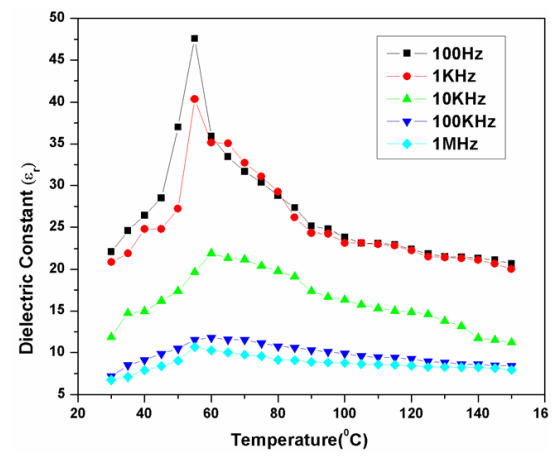

Figure 7: TG/DTA plot of TGP crystal.

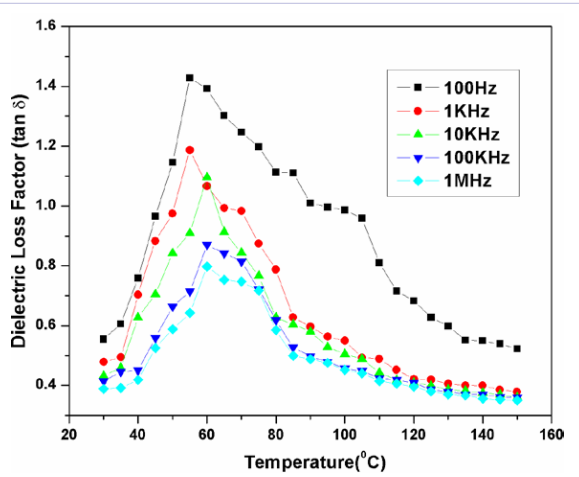

Figure 8: Variation of dielectric constant $\left(\xi_{\text {q }}\right)$ with frequency and temperature.

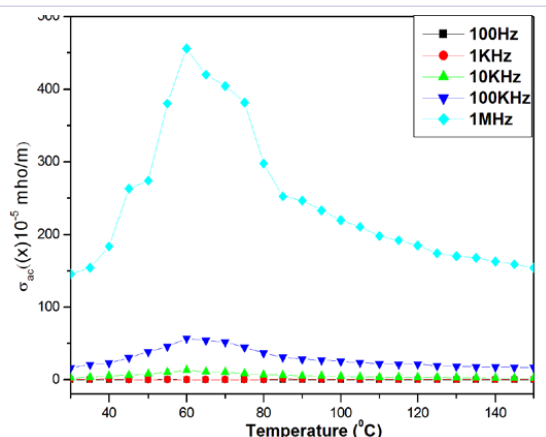

Figure 9: Variation of dielectric loss factor with frequency and temperature. 
for optoelectronic applications. The thermo gravimetric analysis confirms the thermal stability of the grown TGP crystal up to $235{ }^{\circ} \mathrm{C}$. Variations of $\varepsilon_{\mathrm{r}} \tan \delta$, and $\sigma_{\mathrm{ac}}$ values with frequency and temperature shows that the grown crystal is normal dielectric material.

\section{Acknowledgement}

The author Meera MR thanks the University Grants Commission (UGC), India, for the award of a Teacher Fellowship under FDP scheme leading to the Ph.D. degree.

\section{References}

1. Marcy HO, Warnn LF, Webb MS, Eebbers CA, Velsko SP, Kennedy GS et al. Second - harmonic generation in zinc tris (thiourea) sulphate. Appl Opt. 1992;31(24);5051-5060. doi:10.1364/A0.31.005051

2. Xinqiang Wang, Xu D, Yuan DR, Tian YP, Yu WT, Sun SY, et al. Synthesis, structure and properties of a new nonlinear optical material: zinc cadmium tetrathiocyanate. Mater Res Bull. 1999;34(12-13):20032011. doi:10.1016/S0025-5408(99)00211-1.

3. Ying Li, Zhi-Ru Li, Di Wu, Rui-Yan Li, Xi-Yun Hao, Sun CC. An ab Initio Prediction of the Extraordinary Static First Hyperpolarizability for the Electron-Solvated Cluster $(\mathrm{FH}) 2\{\mathrm{e}\}(\mathrm{HF})$. J Phys Chem B. 2004;108(10):3145-3148. doi: 10.1021/jp036808y.

4. Mohan kumar R, Rajan babu D, Jayaraman D, Jayavel R, Kitamura K. Studies on the growth aspects of semi-organic l-alanine acetate a promising NLO crystal." J Cryst Growth. 2005;275(1-2):e1935e1939. doi: 10.1016/j.jcrysgro.2004.11.260

5. Ramesh kumar G, Gokul raj S, Mohan R, Jayaval R. Growth and characterization of new nonlinear optical l-threonium acetate single crystals. J Cryst Growth. 2005;283(1);193-197. Doi:10.1016/j. jcrysgro.2005.04.103.

6. Muralidharan R, Mohan kumar R, Jayaval R, Ramasamy. Growth and characterization of L-arginine acetate single crystals: a new NLO material. J Cryst Growth. 2003;259(3):321-325. doi:10.1016/j. jcrysgro.2003.07.021

7. Tanusri Pal, Tapati Mallik, Tanusree kar, Gabriele Bocelli, Lara Rigi. Growth and characterization of nonlinear optical l-arginine dihydrate single crystals. J Cryst Growth. 2005;285:178-182. doi:10.1016/j. jcrysgro.2005.08.025

8. SL Miller, LE Orgel. The Origins of Life on Earth, Prentice Hall Englewood Cliffs. NJ. 1974

9. Hussaini SS, Dhumane NR, Dongre VG, Shirsat MD. Synthesis, Growth and Characterization of Non-Linear Optical Crystal: Tri-Glycine Acetate (TGAc). Materials Science-Poland. 2009;27(2).

10. LJ Bellamy. The Infrared Spectra of Complex Molecules, Chapman and Hall. London. 1980

11.S Kalainathan and M Beatrice. Preparation of new ferroelectric glycine phosphite single crystals. Mat Sci Engg B. 2005;120(1):190-193. doi:10.1016/j.mseb.2005.02.014.

12. Rajendran K.V, Jayaraman D, Jayavel R, Ramasamy P. Effect of pH on the growth and characterization of l-HFB single crystal. J Cryst Growth. 2003;254(3-4):461-468.doi:10.1016/S0022-0248(03)01097-2.

13. R Parimaladevi, C Sekar. Crystal growth and spectral studies of nonlinear optical g-glycine single crystal grown from phosphoric acid. Spectrochimica Acta Part A. 2010;76(5):490-495.doi: 10.1016/j. saa.2010.04.008. 